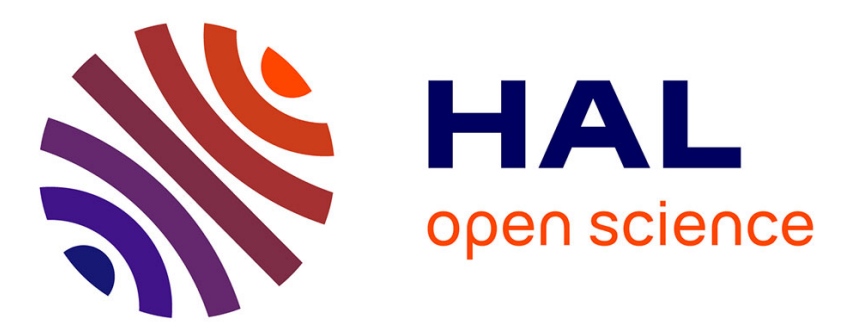

\title{
Prediction of confidence limits for diacetyl concentration during beer fermentation
}

Ioan-Cristian I.-C. Trelea, C. Landaud, Eric Latrille, Georges Corrieu

\section{To cite this version:}

Ioan-Cristian I.-C. Trelea, C. Landaud, Eric Latrille, Georges Corrieu. Prediction of confidence limits for diacetyl concentration during beer fermentation. Journal- American Society of Brewing Chemists, 2002, 60 (2), pp.77-87. hal-02671929

\section{HAL Id: hal-02671929 \\ https://hal.inrae.fr/hal-02671929}

Submitted on 31 May 2020

HAL is a multi-disciplinary open access archive for the deposit and dissemination of scientific research documents, whether they are published or not. The documents may come from teaching and research institutions in France or abroad, or from public or private research centers.
L'archive ouverte pluridisciplinaire HAL, est destinée au dépôt et à la diffusion de documents scientifiques de niveau recherche, publiés ou non, émanant des établissements d'enseignement et de recherche français ou étrangers, des laboratoires publics ou privés. 


\title{
Prediction of Confidence Limits for Diacetyl Concentration During Beer Fermentation
}

\author{
Ioan Cristian Trelea, ${ }^{1}$ Sophie Landaud, Eric Latrille, and Georges Corrieu, Unité mixte de recherche de Génie et \\ Microbiologie des Procédés Alimentaires, Institut National Agronomique Paris-Grignon, Institut National de la \\ Recherche Agronomique, BP 01, 78850 Thiverval-Grignon, France
}

\section{ABSTRACT \\ J. Am. Soc. Brew. Chem. 59(2):77-87, 2001}

A dynamic model for diacetyl production and reduction was developed based on experimental data from 14 laboratory-scale (15-L) lager beer fermentations carried out in various conditions of temperature $\left(10-16^{\circ} \mathrm{C}\right)$, top pressure (50-850 mbar), initial yeast concentration (5-20 million cells per milliliter) and initial wort gravity (1,036-1,099 g/L). Uncertainties due to measurement errors, model parameters, and batch-to-batch variability were described in a probabilistic framework. The model predicts a probability distribution for the final diacetyl concentration from which a median value and an upper boundary, at a specified confidence level, are derived. It is demonstrated that in-line diacetyl measurements at early stages of fermentation greatly reduce the uncertainty about the final diacetyl level in each specific batch.

Keywords: Alcoholic fermentation, Carbon dioxide production, Dynamic model, Probability distribution

\section{RESUMEN}

Predicción de los Límites de Confianza para la Concentración de Diacetilo en Cerveza Durante la Fermentación

Se desarrolló un modelo dinámico para la producción y reducción de diacetilo durante la fermentación, basado en datos experimentales de 14 fermentaciones en el laboratorio (15 L) con cerveza lager; estas fermentaciones se realizaron en diferentes condiciones de temperatura $\left(10-16^{\circ} \mathrm{C}\right)$, sobrepresión (50-850 mbar), concentración inicial de levadura (5-20 millones de células por mililitro) y densidad inicial del mosto (1,036-1,099 g/L). Las incertidumbres debido a los errores de medición, los parámetros del modelo y la variabilidad de lote a lote, fueron descritas en un marco probabilístico. El modelo pronostica una distribución de probabilidad para la concentración final del diacetilo, de cual se deriva un valor de la mediana y del límite superior de la concentración, a un nivel de confianza especificada. Se demuestra que las mediciones de diacetilo en línea en las fases iniciales de la fermentación reducen de manera significativa la incertidumbre de la concentración final de diacetilo de cada lote.

Palabras claves: Fermentación alcohólica, Producción de gas carbónico, Modelo dinámico, Distribución de probabilidad

In most lager beers, diacetyl gives an undesired buttery flavor if present in concentrations above $0.05-0.1 \mathrm{mg} / \mathrm{L}$. Usually, diacetyl is removed either during the dedicated "diacetyl rest" phase or the beer maturation phase. The length and conditions (e.g., temperature) of these phases are greatly influenced by the amount of diacetyl present at the end of the main fermentation. For efficient production scheduling, it is important to predict this concentration as early and as accurately as possible.

Several mathematical models for diacetyl concentration are available in the literature. They are all based on the well-estab-

${ }^{1}$ Corresponding author. E-mail: trelea@grignon.inra.fr

Publication no. J-2002-0401-01R.

(C) 2002 American Society of Brewing Chemists, Inc. lished fact that diacetyl is simultaneously produced and reduced during the fermentation process. The mechanisms they assume or imply are very different, however, and are not always satisfactory from a biochemical point of view. This is probably due to the fact that the production and reduction rates could not be measured separately. In the model proposed by Engasser et al (6), the diacetyl production is proportional to the alcoholic fermentation rate, with a constant yield, while the reduction rate is proportional to the concentration of the reactant in the limiting reaction step. Garcia et al (7) established a model in which the diacetyl production rate depends on the alcoholic fermentation rate, on the biomass concentration, and on the valine consumption rate. The reduction rate involves cell concentration corrected by a cellaging factor. This is not entirely satisfactory because 1) no predictive formula is given for the valine concentration and 2) a rate-limiting step that was shown to be nonenzymatic (18) was assumed to depend on the cell concentration. Gee and Ramirez (8) model the total vicinal diketone concentration, i.e., diacetyl plus 2,3-pentanedione. The drawback of this approach is that the organoleptic threshold of 2,3-pentanedione is at least six times higher than that of the diacetyl (11), while in our experiments the two concentrations are similar. The total concentration can thus hardly be representative of the beer flavor. In the model (8), the diketone production rate is proportional to the specific growth rate and to the cell concentration. The reduction rate is proportional to the total diketone and to the cell concentrations, an assumption that does not correspond to current biochemical knowledge as explained above. Andres-Toro et al (1) divide the biomass into several compartments, only one of which (the active biomass) is involved in diacetyl synthesis. In their model, the diacetyl synthesis rate is proportional to the fermentable sugar concentration and the reduction rate to the ethanol concentration, which is biochemically rather surprising.

The model proposed in the present work was meant to be useful from a process engineering perspective. It has several features. First, it is based on a predictive model for the alcoholic fermentation (17). The progress of the alcoholic fermentation is routinely monitored in the brewery, via gravity and possibly evolved $\mathrm{CO}_{2}$ and/or refractive index measurements $(5,13)$. In case of discrepancies, the model can be easily adapted for each particular batch (4). Second, it does not involve quantities usually unmeasured in industry such as valine concentration, active yeast concentration, or specific growth rate. Third, it does not try to describe the intricacy of the diacetyl production mechanism but is compatible with the current understanding of biochemical pathways. Fourth, special emphasis is placed on the reliability of the predictions, on the sources of uncertainty, and of the ways to reduce them through in-line measurements. Fifth, the model was validated in a wide range of operating conditions: fermentation temperatures between 10 and $16^{\circ} \mathrm{C}$, top pressures between 50 and 850 mbar, initial cell concentrations between 5 and 20 million cells per milliliter, and initial wort densities between 1,036 and $1,099 \mathrm{~kg} / \mathrm{m}^{3}$. 


\section{EXPERIMENTAL}

Experiments were carried out in 15-L, 0.5-m-high stainless steel tanks (LSL Biolafitte, St. Germain-en-Laye, France) under gentle agitation at $100 \mathrm{rpm}$. Preliminary experiments showed that mechanical agitation was needed to compensate for the absence of the natural agitation that occurs in large-scale brewing (10-mhigh tanks or higher) due to $\mathrm{CO}_{2}$ release. The lager wort and the industrial yeast strain, Saccharomyces cerevisiae var. uvarum, were provided by the Institut Français de Brasserie et Malterie (Vandoeurvre-les-Nancy, France). Run R12 was carried out with a different wort, "Cedarex light hopped wort" provided by Munton and Fison, Stowmarket, UK. Starter cultures were grown at $20^{\circ} \mathrm{C}$ in $5 \mathrm{~L}$ of wort for three days. The temperature was decreased to fermentation temperature one day before inoculation, and the starter cultures were centrifuged three times $(4,000 \mathrm{rpm})$ in physiological saline. The conditions of the experimental runs were selected according to a $2^{3}$ experimental design, as indicated in Table I. The factors were the fermentation temperature, the top pressure, and the initial yeast concentration. Runs R01-R04 and R06-R09 were performed under extreme operating conditions, while runs R05 and R13-R15 were intended to be repetitions of the central point of the experimental design and $\mathrm{R} 11$ a repetition of R03. Run R10 was atypical because of its very high initial wort gravity and run R12 because of the different wort. Due to experimental uncertainty, the initial cell concentration, the initial wort gravity, and the lowest top pressure could not be replicated exactly. The actual (measured) values of these factors are indicated in Table I.

The concentrations of diacetyl and of its precursor, $\alpha$-acetolactate, were determined by gas chromatography coupled with mass spectrometry (9). The ethanol concentration was determined using a gas chromatograph (5300, Carlo Erba, Nanterre, France) equipped with a stainless steel column $(200 \mathrm{~mm}, \varnothing 0.3 \mathrm{~mm})$ coated with Chromosorb 101 (SGE, Courtaboeuf, France). The concentration of fermentable sugar (the sum of the concentrations of fructose, glucose, maltose, and maltotriose) was determined using a high-performance liquid chromatography system (Waters, Millford, MA) with a 300-mm, $\varnothing 7.8-\mathrm{mm}$ column (Aminex HPX$87 \mathrm{C}, \mathrm{BioRad})$ at $85^{\circ} \mathrm{C}$. The density of the filtered and degassed wort was determined with a $10-\mathrm{ml}$ pycnometer. The refractive index was measured with a refractometer (ATAGO, Illkirch, France). The evolved $\mathrm{CO}_{2}$ was recorded with a gas meter (Schlumberger, Colombes, France), delivering a pulse for every liter of gas. Taking into account the amounts of $\mathrm{CO}_{2}$ produced in the considered experiments, the resolution of this measurement was better than $0.5 \%$. The measurements describing the alcoholic fermentation (ethanol, density, $\mathrm{CO}_{2}$ production, refractive index, and fermentable sugar) were reconciled using well-established stoichiometric relationships (16). The yeast cell concentration was determined with a particle counter (Coulter Z1, Coultronics, Gagny, France). Three counts were performed at 3 and $3.5 \mu \mathrm{m}$, and the logarithmic average of the six counts was taken.

\section{Biochemical Background of the Dynamic Model}

Relevant pathways involved in diacetyl synthesis and degradation are schematically represented in Figure 1. Quantitatively, the main mass flow is from fermentable sugars (in beer fermentation, these are mainly maltose and glucose) to ethanol and $\mathrm{CO}_{2}$. About $94 \%$ of the carbon flows through this pathway, called "alcoholic fermentation" in this article. An intermediate product, important for many cell functions including diacetyl synthesis, is pyruvate. In our experiments, the carbon flow rate from pyruvate to $\alpha$-acetolactate was about three orders of magnitude lower than from pyruvate to ethanol and $\mathrm{CO}_{2}$. The actual rate is the result of complex interactions and internal cell regulation. The reaction step from $\alpha$-acetolactate to diacetyl is purely chemical (nonenzymatic). Diacetyl is transformed enzymatically into 2,3-butanediol, whose contribution to the beer flavor is negligible.

From this simplified picture of the biological reality, plausible modeling assumptions can be formulated. First, since the rate of the alcoholic fermentation is an important indicator of cell meta-

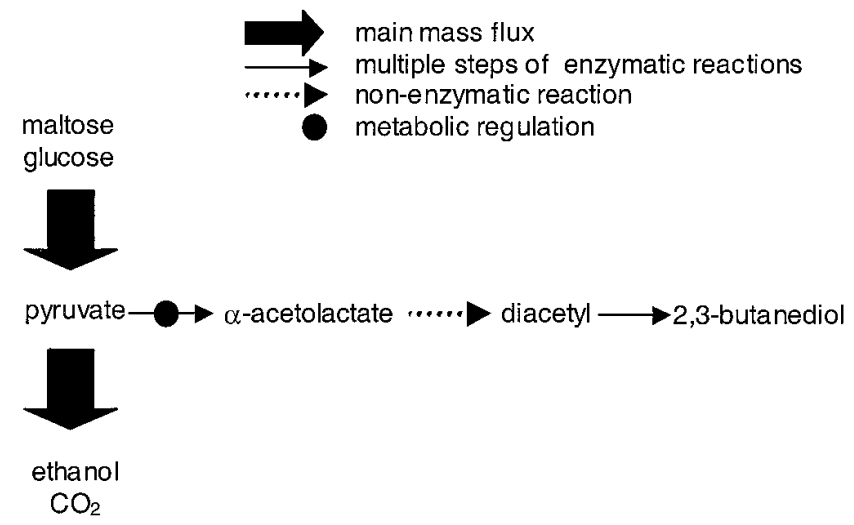

Fig. 1. Main biochemical pathways involved in diacetyl synthesis and reduction.

TABLE I

Experimental Conditions ${ }^{\mathrm{a}}$

\begin{tabular}{|c|c|c|c|c|}
\hline Experimental Run & Temperature $\left({ }^{\circ} \mathbf{C}\right)$ & Top Pressure (mbar) & Initial Yeast Concentration $\left(10^{6}\right.$ cells $\left.\mathrm{ml}^{-1}\right)$ & Initial Wort Density $\left(\mathrm{g} \mathrm{L}^{-1}\right)$ \\
\hline R01 & $10(\mathrm{~L})$ & $800(\mathrm{H})$ & $40(\mathrm{H})$ & 1,070 \\
\hline $\mathrm{R} 02$ & $10(\mathrm{~L})$ & $60(\mathrm{~L})$ & $19(\mathrm{H})$ & 1,037 \\
\hline R03 & $10(\mathrm{~L})$ & $50(\mathrm{~L})$ & $6(\mathrm{~L})$ & 1,049 \\
\hline R05 & $13(\mathrm{C})$ & $450(\mathrm{C})$ & $10(\mathrm{C})$ & 1,049 \\
\hline R06 & $16(\mathrm{H})$ & $50(\mathrm{~L})$ & $20(\mathrm{H})$ & 1,047 \\
\hline R07 & $16(\mathrm{H})$ & $800(\mathrm{H})$ & $22(\mathrm{H})$ & 1,051 \\
\hline R08 & $16(\mathrm{H})$ & $790(\mathrm{H})$ & $5(\mathrm{~L})$ & 1,051 \\
\hline R11 & $10(\mathrm{~L})$ & $70(\mathrm{~L})$ & $6(\mathrm{~L})$ & 1,048 \\
\hline $\mathrm{R} 12 * *$ & $13(\mathrm{C})$ & 450 (C) & $10(\mathrm{C})$ & 1,046 \\
\hline R13 & $13(\mathrm{C})$ & $450(\mathrm{C})$ & $14(\mathrm{C})$ & 1,051 \\
\hline R14 & $13(\mathrm{C})$ & 450 (C) & $10(\mathrm{C})$ & 1,050 \\
\hline R15 & $13(\mathrm{C})$ & 390 (C) & 9 (C) & 1,049 \\
\hline
\end{tabular}

${ }^{a} \mathrm{~L}=$ Low value in the experimental design, $\mathrm{H}=$ high value in the experimental design, $\mathrm{C}=$ central value in the experimental design, $*=$ atypical run: higher initial wort density, and $* *$ atypical run: different wort. 
bolism, the $\alpha$-acetolactate production rate should be closely related to it. However, the fraction of the carbon flow diverted through this pathway is not necessarily constant. Second, because the reaction steps from diacetyl to 2,3-butanediol are much faster than from $\alpha$-acetolactate to diacetyl, the concentration of the diacetyl during the alcoholic fermentation is negligible compared with that of $\alpha$-acetolactate $(9,10)$. After complete yeast removal by filtration, however, diacetyl cannot be reduced further and may accumulate in the finished beer if $\alpha$-acetolactate is still present. So, what is actually important for the finished beer flavor is the total concentration of diacetyl plus equivalent $\alpha$-acetolactate, also called "total" or "potential" diacetyl. It is this total concentration that is modeled in this article, and it is called "diacetyl" for brevity. Third, in the presence of yeast, the rate of removal of the "total" diacetyl is given by the limiting rate of the chemical reaction step from $\alpha$-acetolactate to diacetyl and thus is independent of the yeast concentration. This is the case for the model of Engasser et al (6) but not for the other models discussed above $(1,7,8)$.

\section{Alcoholic Fermentation Model}

The dynamic model for the alcoholic fermentation was developed previously $(15,17)$ and is briefly recalled here for completeness. It was constructed by analogy with classical microbial growth kinetics with substrate limitation and product inhibition (Appendix I). Terms are defined in Appendix II.

$$
\begin{gathered}
\frac{d C_{p}(t)}{d t}=v\left[\theta(t), C_{\mathrm{d}}(t)\right] \cdot \frac{S(t)}{K_{S}+S(t)} \cdot \frac{1}{1+\left[E(t) / K_{E}\right]^{2}} \cdot\left[C_{p}(t)+K_{x} X_{0}\right] \\
C_{p}(0)=0 \\
E(t)=Y_{E / C} C_{p}(t) \\
S(t)=S_{0}-Y_{S / C} C_{p}(t)
\end{gathered}
$$

In Equation 1, the rate of the alcoholic fermentation was described by the rate of $\mathrm{CO}_{2}$ production $d C_{p} / d t$. Simultaneously, ethanol $(E)$ is produced and fermentable sugars $(S)$ are consumed, with constant yields (equations 2 and 3 ). The initial fermentation rate, when $C_{p}=0$, is taken proportional to the initial yeast concentration $X_{0}$. The "specific" fermentation rate $v$ is given by:

$$
v\left(\theta, C_{d}\right)=K_{v} \exp \left[K_{v \theta}\left(\theta-\theta_{0}\right)-K_{\nu C}\left(C_{d}-C_{d 0}\right)\right]
$$

For small temperature variations $( \pm 3 \mathrm{~K})$ compared to the typical absolute fermentation temperature $(286 \mathrm{~K})$, Equation 4 is a close approximation of the Arrhenius law. A similar dependence was assumed for the dissolved $\mathrm{CO}_{2}\left(C_{d}\right)$. For modeling purposes, it was assumed that the produced $\mathrm{CO}_{2}\left(C_{p}\right)$ was dissolved in the wort until saturation $\left(C_{s a t}\right)$, and released afterwards $\left(C_{r}\right)$ :

$$
\begin{gathered}
C_{d}(t)=\min \left\{C_{p}(t), C_{\text {sat }}(\theta, p)\right\} \\
C_{r}(t)=\max \left\{0, C_{p}(t)-C_{\text {sat }}(\theta, p)\right\}
\end{gathered}
$$

The wort saturation with $\mathrm{CO}_{2}$ was determined using an empirical formula, based on tables of experimental values provided by the Institut Français de Brasserie et Malterie:

$$
\begin{gathered}
C_{s a t}(\theta, p)=H(\theta) p \\
H(\theta)=K_{0}\left(1+K_{1} \theta\right) \exp \left(-K_{2} \theta\right)
\end{gathered}
$$

In applications, model predictions should be compared with available measurements and model adaptation steps possibly taken (4). Equation 6 assumed that the released $\mathrm{CO}_{2}$ was measured. If the measured quantity was the wort density $(D)$ or the refractive index $(R)$, the following equations should be used instead:

$$
\begin{gathered}
D(t)=D_{0}-Y_{D / C} C_{p}(t) \\
R(t)=R_{0}-Y_{R / C} C_{p}(t)
\end{gathered}
$$

Numerical values for the coefficients involved in the alcoholic fermentation model are reported in Table II. They were either taken from literature or determined from available experimental data. Runs R01-R04 and R06-R09 were used for parameter identification and the other runs for model validation. The model parameters were determined using a standard maximum likeli-

\begin{tabular}{|c|c|c|c|c|c|c|}
\hline \multirow[b]{2}{*}{ Symbol } & \multirow[b]{2}{*}{ Units } & \multicolumn{3}{|c|}{ Value with $95 \%$ Confidence Limits } & \multirow[b]{2}{*}{ Distribution $^{b}$} & \multirow[b]{2}{*}{ Source } \\
\hline & & Min. & Median & Max. & & \\
\hline$\theta_{0}$ & ${ }^{\circ} \mathrm{C}$ & NA & 13 & NA & None & Central condition of the experimental design \\
\hline$C_{\mathrm{d} 0}$ & $\mathrm{~g} \cdot \mathrm{L}^{-1}$ & NA & 2.76 & NA & None & Central condition of the experimental design \\
\hline$K_{v}$ & $\mathrm{hr}^{-1}$ & 0.0415 & 0.0450 & 0.0488 & Log-normal & $\begin{array}{l}\text { Determined from runs } \mathrm{R} 1-\mathrm{R} 4 \text { and } \mathrm{R} 6-\mathrm{R} 9 \text { with a } \\
\text { maximum likelihood method }\end{array}$ \\
\hline$K_{v \theta}$ & ${ }^{\circ} \mathrm{C}^{-1}$ & 0.118 & 0.125 & 0.131 & Normal & Idem \\
\hline$K_{V C}$ & $\mathrm{~g}^{-1} \cdot \mathrm{L}$ & 0.020 & 0.055 & 0.090 & Normal & Idem \\
\hline$K_{E}$ & $g \cdot \mathrm{L}^{-1}$ & 20.7 & 22.6 & 24.7 & Log-normal & Idem \\
\hline$K_{S}$ & $\mathrm{~g} \cdot \mathrm{L}^{-1}$ & ND & 3 & ND & None & References $(1,7,8)$ \\
\hline$K_{X}$ & $\mathrm{~g} \cdot \mathrm{L}^{-1} \cdot\left(10^{6} \text { cells }\right)^{-1}$ & 0.120 & 0.143 & 0.173 & Log-normal & $\begin{array}{l}\text { Determined from runs } \mathrm{R} 1-\mathrm{R} 4 \text { and } \mathrm{R} 6-\mathrm{R} 9 \text { with a } \\
\text { maximum likelihood method }\end{array}$ \\
\hline$K_{0}$ & $\mathrm{~g} \cdot \mathrm{L}^{-1} \cdot \mathrm{mbar}^{-1}$ & ND & $2.83 \cdot 10^{-5}$ & ND & None & $\begin{array}{l}\text { Regression with experimental data from tables used } \\
\text { by professional brewers }\end{array}$ \\
\hline$K_{1}$ & ${ }^{\circ} \mathrm{C}^{-1}$ & ND & $3.66 \cdot 10^{-3}$ & ND & None & Idem \\
\hline$K_{2}$ & ${ }^{\circ} \mathrm{C}^{-1}$ & ND & $3.35 \cdot 10^{-2}$ & ND & None & Idem \\
\hline$Y_{D / C}$ & $g \cdot g^{-1}$ & NA & 1 & NA & None & Reference (16) \\
\hline$Y_{E / C}$ & $\mathrm{~g} \cdot \mathrm{g}^{-1}$ & 1.013 & 1.028 & 1.043 & Normal & Idem \\
\hline$Y_{R / C}$ & $\mathrm{~g}^{-1} \cdot \mathrm{L}$ & $2.440 \cdot 10^{-4}$ & $2.494 \cdot 10^{-4}$ & $2.548 \cdot 10^{-4}$ & Normal & Idem \\
\hline$Y_{\mathrm{S} / \mathrm{C}}$ & $\mathrm{g} \cdot \mathrm{g}^{-1}$ & 1.834 & 1.884 & 1.934 & Normal & Idem \\
\hline
\end{tabular}
hood method, based on ethanol, fermentable sugar, wort density, and wort refractive index measurements simultaneously. This is equivalent to a nonlinear least-squares model fitting provided that each measurement is weighted by the inverse of the standard deviation of its measurement error (16). Numerical computations were performed using the Levenberg-Marquardt minimization method for nonlinear sums of squares implemented in the Matlab software package (3). Reasonable initial values for the model

TABLE II

Numerical Values of the Coefficients in the Alcoholic Fermentation Model ${ }^{\text {a }}$

a $\mathrm{ND}=$ not determined and $\mathrm{NA}=$ not applicable.

${ }^{b}$ Assumed distribution for the estimator. 
parameters were determined by repeated simulation and graphical comparison of experimental and predicted data.

\section{Diacetyl Production and Removal}

As discussed previously, in presence of the yeast, the "total" diacetyl concentration is almost equal to the $\alpha$-acetolactate concentration $(A)$. The rate of its conversion to 2,3-butanediol is limited by a nonenzymatic reaction step and hence should depend on the current $\alpha$-acetolactate concentration, on temperature, and on the characteristics of the medium (composition, $\mathrm{pH}$, redox potential, etc.). The rate of $\alpha$-acetolactate production was assumed to depend on the overall metabolic activity of the yeast, described by the rate of the alcoholic fermentation $d C_{p} / d t$ :

$$
\begin{aligned}
\frac{d A(t)}{d t} & =Y_{A / C}(t) \frac{d C_{p}(t)}{d t}-K_{A} \exp \left[K_{A \theta}\left(\theta-\theta_{0}\right)\right] \cdot A(t) \\
A(0) & =0
\end{aligned}
$$

The characteristics of the microorganism and of the medium are included in the model through the numerical values of the diacetyl yield $\left(Y_{A / C}\right)$, the diacetyl reduction constant $\left(K_{A}\right)$, and the temperature sensitivity constant $\left(K_{A \theta}\right)$. These values are thus specific for each yeast strain-wort type couple. The model of Engasser et al (6) has the same form as equation 11, with the sugar consumption rate replacing the $\mathrm{CO}_{2}$ production rate (which is equivalent, as the ratio of the two rates is nearly constant) and with a constant yield $Y_{A / C}$. When trying to fit equation 11 to experimental data from any of the runs R01-R15, however, it turned out that the constant-yield hypothesis implied that, as soon as the active fermentation phase was over (sugar depletion), the acetolactate concentration should almost immediately fall to zero. This sharp fall was not observed. Rather, even after complete sugar exhaustion, the acetolactate concentration continued to decline slowly. Because the prediction of diacetyl level after the end of the alcoholic fermentation was of the highest practical importance, the model based on the constant-yield hypothesis was judged unsatisfactory. Data presented by Engasser et al (6) stop before the end of the main fermentation so that the abovementioned discrepancy in their model could not be assessed. The failure of the constant-yield model to describe the data can be explained as follows. The maximum of the $\alpha$-acetolactate concentration appears nearly at the same time as the maximum of the alcoholic fermentation rate. To describe this, a constant-yield model needs high values for both $Y_{A / C}$ and $K_{A}$, meaning that the $\alpha$ acetolactate is reduced almost immediately after being produced.

The experimental data could be described by equation 11 by supposing a variable yield: $Y_{A / C}$ should be maximum at the beginning of the fermentation and fall to zero well before the fermentable sugar depletion. Resulting numeric values for $Y_{A / C}$ and $K_{A}$ were much less than in the constant-yield case, meaning that $\alpha$ acetolactate was produced during the first half of the fermentation, accumulated into the medium, and then declined slowly. The following empirical equation was found to describe the yield variation adequately:

$$
\begin{aligned}
& \frac{d Y_{A / C}(t)}{d t}=-K_{Y} \frac{d C_{p}(t)}{d t} \cdot Y_{A / C}(t) \\
& Y_{A / C}(0)=Y_{O}
\end{aligned}
$$

Again, the alcoholic fermentation rate $d C_{p} / d t$ was used to describe the intensity of the metabolic activity. It should be emphasized that, while equation 11 is based on biochemical insight, equation 12 is purely descriptive. The cell regulation mechanisms that make the acetolactate production stop well before fermentable sugar exhaustion were not investigated in this work. It is worth noting that linking diacetyl production to cell growth instead of progress in alcoholic fermentation would result (for the considered database) in an equivalent model since propor- tionality between yeast growth and alcoholic fermentation progress was observed (Appendix I). Proportionality does not necessarily hold in general (e.g., due to yeast settling in naturally agitated tanks) but does often hold in the early stages of the fermentation, when diacetyl is produced.

\section{Sources of Uncertainty in Model Parameter Estimation}

To obtain practically useful predictions of the total diacetyl concentration during alcoholic fermentation, numerical values for the parameters appearing in equations 11 and 12 had to be found using some experimental runs, and the validity of the predictions had to be checked using the remaining runs. Mathematical predictions of physical reality are always subject to some uncertainty, but in the present study, the uncertainties were found to be large enough to be worth detailed study.

Diacetyl measurement error. The usual concentrations of diacetyl in beer are less than $1 \mathrm{mg} / \mathrm{L}$, and their determination required complex experimental work (9). The results were affected by unavoidable experimental error traditionally described by a Gaussian probability distribution with zero mean and unknown standard deviation $\sigma_{\mathrm{A}}$. Let $I$ denote the set of runs used for model parameter identification, $n_{\mathrm{i}}$ the number of diacetyl measurements, and $Y_{0 i}$ the initial diacetyl yield in run $i$. Let $w$ be the vector of the unknown model parameters in equations 11 and 12:

$$
w=\left[\begin{array}{lllllll}
\log K_{A} & K_{A \theta} & \log K_{Y} & \log Y_{01} & \ldots & \log Y_{0 i} \ldots
\end{array}\right]^{T}, \quad i \in I
$$

The logarithms of the unknown scale parameters were determined instead of the parameters themselves. From a practical perspective, this ensured positiveness and increased numerical robustness and accuracy. The theory also states that, if the order of magnitude is a priori unknown, parameters should be located uniformly on a logarithmic scale (12).

If $a_{i j}$ is the measured total diacetyl concentration in sample $j$ of the experiment $i$ and $A_{i j}(w)$ is the value predicted by the model with unknown parameters set to $w$, then the probability density of observing the given set of measurements, also called the likelihood of the sample, is given by (2):

$$
\text { likelihood }=\frac{1}{\left(\sigma_{A} \sqrt{2 \pi}\right)^{n}} \prod_{i \in I} \prod_{j=1}^{n_{i}} \exp \left(-\frac{\left[A_{i j}(w)-a_{i j}\right]^{2}}{2 \sigma_{A}^{2}}\right)
$$

Here $n=\sum_{i \varepsilon I}^{n_{i}}$ is the total number of available measurements.

The value $w^{*}$, which maximizes the likelihood, is called the maximum likelihood estimator of the unknown model parameters. It is mathematically equivalent, but numerically more convenient, to minimize the minus logarithm of the likelihood function $L(w)$ :

$$
\begin{gathered}
L(w)=n \log \sigma_{A}+\frac{n}{2} \log 2 \pi+\frac{1}{2 \sigma_{A}^{2}} M(w) \\
M(w)=\sum_{i \in I} \sum_{j=1}^{n_{i}}\left[A_{i j}(w)-a_{i j}\right]^{2}
\end{gathered}
$$

The sum of squares $M(w)$ is independent of $\sigma_{A}$ and was minimized numerically using a Levenberg-Marquardt algorithm (3), giving:

$$
w^{*}=\arg \min M(w)
$$

Initial values of the parameters required by the numerical minimization algorithm were determined by repeated simulation and graphical comparison of the predicted and measured values. Differentiating equation 15 with respect to $\sigma_{A}$ and setting the derivative to zero yields a slightly biased estimator of the measurement standard deviation. The related, but unbiased, version of this estimator is (2): 


$$
\sigma_{A}=\sqrt{\frac{M\left(w^{*}\right)}{n-n_{w}}}
$$

where $n_{w}$ is the number of the parameters to be estimated and $n-$ $n_{w}$ is the number of degrees of freedom.

Model parameter uncertainty. Dynamic model parameters can be determined with finite accuracy only from equation 17 due to the presence of measurement noise. When the number of degrees of freedom is sufficiently large (larger than for example 50, which was the case in this study) the maximum likelihood estimator $w^{*}$ of the unknown parameter vector $w$ is unbiased and has an approximately normal sampling distribution with a covariance matrix $V$ that can be calculated numerically as the inverse of the local information matrix (2):

$$
V=\left[\frac{\partial^{2} L}{\partial w \partial w^{T}}\left(w^{*}\right)\right]^{-1}
$$

Batch to batch variation of the initial diacetyl yield. Equation 13 indicates that the model parameters $K_{A}, K_{A \theta}$, and $K_{Y}$ were supposed common to all runs, i.e., constant for a given combination of wort and yeast strain, while the initial diacetyl yields $Y_{0 i}$ were determined specifically for each run. A common diacetyl yield for all runs, or a model based on measured quantities, could not be determined. Repetitions of the same run (within experimental error: e.g., R03-R11, R13-R15) exhibited differences in diacetyl level as large as 1:2 (see the Results and Discussion section below). Such variations, in otherwise similar fermentation runs, were also observed by other authors (e.g., Figs. 2 and 3 in ref. 14). Exact causes could not be determined. After careful examination across all runs, particularly low or high diacetyl levels could not be correlated satisfactorily with any of the following measurements: temperature, top pressure, initial yeast concentration, yeast growth rate, initial dissolved oxygen concentration, evolution of $\mathrm{pH}$, redox potential and electrical conductivity during the batch, alcoholic fermentation rate, or amino acid uptake. It should be noted that the observed variations in the initial diacetyl yield were far larger than the uncertainties due to measurement errors.

In the absence of a satisfactory deterministic model, the batchto-batch variations of the initial diacetyl yields were described by a probability distribution. Among the various distributions tested (normal, log-normal, exponential, and gamma), the log-normal distribution was the most plausible in the light of the data (initial yields determined for runs R01-R11 and R13-R15). In particular, the normal distribution predicted overly low probabilities for the highest yields; they wouldn't have a reasonable chance of appearing in a sample of 14 runs. The choice of a log-normal distribution is consistent with equation 13 and can be interpreted in the light of a central limit theorem: the value of the diacetyl yield in a particular run is influenced by a large number of multiplicative causes. The probability density function of the log-normal distribution is (2):

$$
f\left(Y_{0}\right)=\frac{1}{Y_{0} \lambda \sqrt{2 \pi}} \exp \left[-\frac{1}{2}\left(\frac{\log Y_{0}-\mu}{\lambda}\right)^{2}\right]
$$

A log-normal distribution for $Y_{0}$ means that $\log Y_{0}$ is distributed normally. The parameter $\mu$ represents the expected value of $\log$ $Y_{0}$, and $\lambda$ represents its standard deviation. However, some care is needed when transposing results from the normal to the lognormal distribution because of its asymmetric shape. For a normal distribution, the mean (expected value), the median (value below and above which $50 \%$ of the random samples fall), and the mode (most probable value) are all the same. For a log-normal distributed variable, the median is still $\exp (\mu)$, but the mean is $\exp (\mu+$ $\left.0.5 \cdot \lambda^{2}\right)$ and the mode is $\exp \left(\mu-\lambda^{2}\right)$. In order to avoid confusion, results will be presented in terms of the median value.
The maximum likelihood estimator for $\mu$ is unbiased, with minimum variance (2):

$$
\mu=\frac{1}{n_{r}} \sum_{i=1}^{n_{r}} \log Y_{0 i}
$$

where $n_{r}$ is the number of runs used for statistical parameter estimation. The unbiased version of the estimator for $\lambda$ is:

$$
\lambda=\sqrt{\frac{1}{n_{r}-1} \sum_{i=1}^{n_{r}}\left(\log Y_{0 i}-\mu\right)^{2}}
$$

Determination of the initial diacetyl yield for a specific batch. Equations 13-19 are useful in the model identification step when one uses data from several runs to determine fixed-model parameters $K_{A}, K_{A \theta}, K_{Y}$, and $\sigma_{A}$. In doing so, however, one also has to determine initial yields for those runs. Equations 20-22 apply when one wishes to determine a priori plausible values for the diacetyl yield for a given wort and yeast strain combination. Another intermediate situation is likely to appear in practice: one already knows the constant-model parameters $K_{A}, K_{A \theta}$, and $K_{Y}$ but wishes to determine the diacetyl yield for a specific batch using available measurements performed with known accuracy $\sigma_{A}$. In this case, equation 13 reduces to:

$$
w=\left[\log Y_{0}\right]
$$

Equations 14-17 and 19 remain valid for this particular case of a single unknown parameter.

\section{Prediction of the Diacetyl Concentration in the Presence of Uncertainty}

The time evolution of the diacetyl concentration was predicted by the dynamic model consisting of equations $1-12$. The alcoholic fermentation model (equations 1-10) turned out to be at least an order of magnitude more accurate than the diacetyl model (equations 11 and 12). The alcoholic fermentation model was considered deterministic, and the corresponding uncertainty was neglected throughout this study. Other sources of uncertainty were taken into account selectively, depending on the model usage and on the information at hand.

Prediction without in-line diacetyl concentration measurements. To predict the diacetyl concentration in a run where no diacetyl measurements would be performed, it was assumed that 1) constant-model parameters $\log K_{A}, K_{A \theta}$, and $\log K_{\mathrm{Y}}$ (equation 13) have a joint normal probability distribution with mean $w^{*}$ (equation 17) and covariance $V$ (equation 19); 2) in the absence of any information for that specific batch, the logarithm of the initial diacetyl yield $\log Y_{0}$ has a normal probability distribution (equation 20) with mean $\mu$ and standard deviation $\lambda$ (equations 21 and 22); and 3) the measurement error has a normal probability distribution with zero mean and standard deviation $\sigma_{A}$ (equation 18).

Let $A\left(t, w^{*}\right)$ be the diacetyl concentration predicted by the model (equations 11 and 12) for time $t$, with model parameters set to $w^{*}$. The actual (or true) diacetyl concentration in a given run is generally different from the predicted one because the model parameters cannot be determined exactly. To state the accuracy of the model predictions rigorously, confidence limits for the true diacetyl concentration were calculated with the "error propagation" formula:

$$
\begin{aligned}
& \underline{A}(t)=A\left(t, w^{*}\right)+\sqrt{\frac{\partial A}{\partial w^{T}}\left(t, w^{*}\right) \cdot V \cdot \frac{\partial A}{\partial w}\left(t, w^{*}\right)} \cdot U_{a / 2} \\
& \bar{A}(t)=A\left(t, w^{*}\right)+\sqrt{\frac{\partial A}{\partial w^{T}}\left(t, w^{*}\right) \cdot V \cdot \frac{\partial A}{\partial w}\left(t, w^{*}\right)} \cdot U_{1-a / 2}
\end{aligned}
$$


Here $\underline{A}(t)$ and $\bar{A}(\mathrm{t})$ are the lower and upper boundaries, respectively, for the true diacetyl concentration at the confidence level $\alpha$. Stated another way, the true (and generally unknown) diacetyl concentration has the (small) probability $\alpha$ of being either less than $\underline{A}(t)$ or greater than $\bar{A}(\mathrm{t}) . U$ is the cumulative distribution function of the standard normal distribution (zero mean and unit variance). It should be noted that the first three elements of the vector $w\left(\log K_{A}, K_{A \theta}\right.$, and $\left.\log K_{Y}\right)$, and the corresponding threeby-three block in matrix $V$ were determined in the preliminary model identification step using runs included in the identification set $I$. The fourth element of $w$ is the expected value for $\log Y_{0}$, that is $\mu$, and the corresponding diagonal $(4,4)$ element in $V$ is the estimation of its variance, that is, $\lambda^{2}$. The remaining one-by-three and three-by-one blocks in $V$, representing covariances between $\log Y_{0}$ on one hand and $\log K_{A}, K_{A \theta}$, and $\log K_{Y}$ on the other hand, are set to zero since they are determined separately.

If diacetyl concentration measurements are performed, the measured concentration $a(t)$ is generally different from the actual (or true) one due to unavoidable measurement errors. The confidence limits given by equations 24 and 25 are not appropriate for the measured values because they do not take into account the measurement error. Lower and upper confidence limits, $\underline{a}(\mathrm{t})$ and $\bar{a}(\mathrm{t})$, respectively, of the measured diacetyl concentration were determined as:

$$
\begin{array}{r}
\underline{a}(t)=A\left(t, w^{*}\right)=\sqrt{\frac{\partial A}{\partial w^{T}}\left(t, w^{*}\right) \cdot V \cdot \frac{\partial A}{\partial w}\left(t, w^{*}\right)+\sigma_{A}^{2}} \cdot U_{a / 2} \\
\bar{a}(t)=A\left(t, w^{*}\right)+\sqrt{\frac{\partial A}{\partial w^{T}}\left(t, w^{*}\right) \cdot V \cdot \frac{\partial A}{\partial w}\left(t, w^{*}\right)+\sigma_{A}^{2}} \cdot U_{1-a / 2}
\end{array}
$$

with the standard the assumption of independent normally distributed measurement noise.

Prediction with in-line diacetyl concentration measurements. If diacetyl measurements could be performed during the fermentation, information would be gained about the diacetyl yield for each specific batch. For such cases, the following assumptions were made: 1) the constant model parameters $\log K_{A}, K_{A \theta}$, and $\log K_{Y}$ (equation 13) have the same joint normal probability distribution as above, estimated from previous runs and fixed; 2) the logarithm of the initial diacetyl yield $\log Y_{0}$ is estimated in real-time from in-line data and has an independent normal probability distribution with mean given by equation 17 and variance given by equation 19 , both reduced to the single-parameter case (equation 23); and 3) the measurement error has a normal probability distribution with zero mean and standard deviation $\sigma_{A}$ determined from previous runs and fixed.

Confidence limits for the predicted diacetyl concentration were calculated as before (equations 24-27), except that the fourth element of the parameter vector $w$ was given by equations 17 and 23 instead of $\mu$, and the $(4,4)$ element of the covariance matrix $V$ was given by equations 19 and 23 instead of $\lambda^{2}$.

\section{RESULTS AND DISCUSSION}

\section{Diacetyl Model Identification and Validation}

The parameters of the dynamic diacetyl model $\left(K_{A}, K_{A \theta}\right.$, and $\left.K_{Y}\right)$ as well as the experimental spread of the measurement of the diacetyl concentration $\left(\sigma_{A}\right)$ were determined using eight runs, namely R01-R04 and R06-R09, performed under extreme conditions of temperature, top pressure, and initial yeast concentration (Table I). The median values and the confidence intervals are reported in Table III.

The prediction of the diacetyl concentration using this model is illustrated in Figure 2. The initial $\mathrm{CO}_{2}$ evolution rate is zero, since the $\mathrm{CO}_{2}$ is first dissolved in the wort. This is confirmed by the measured evolution rate. However, the initial simulated $\mathrm{CO}_{2}$ production rate is nonzero and equals $0.23 \mathrm{~g} \cdot \mathrm{L}^{-1} \cdot \mathrm{hr}^{-1}$ in the considered run. During the first $20 \mathrm{hr}$, the diacetyl production rate (not shown) is high and nearly constant, the acceleration in the alcoholic fermentation rate being compensated for by the decrease in the diacetyl yield. The maximum of the diacetyl concentration is reached when the production rate equals the reduction rate. After $35 \mathrm{hr}$, the diacetyl yield is so low that the diacetyl production rate becomes negligible compared to the reduction rate, and the predicted diacetyl concentration decreases exponentially.

\section{Verification of the Statistical Hypothesis}

Several statistical assumptions have been made concerning the diacetyl measurement error and the batch-to-batch variation of the diacetyl yield. These assumptions must be verified in light of the data before conclusions can be drawn about the uncertainty in the model parameters and its effect on the prediction of the diacetyl concentration.

The confidence interval for the mean of the model residuals was $\left[\begin{array}{lll}-0.031 & 0.015\end{array}\right] \mathrm{g} \cdot \mathrm{L}^{-1}$; hence the mean was not significantly different from zero. The normality of the residuals was tested using the modified Anderson-Darling statistic (2). The normality hypothesis could not be rejected at a 0.05 significance level. Additional assurance about the normality hypothesis was provided by the statistical plot in Figure 3A. Thus, the assumption about the zeromean normal distribution of the measurement noise was satisfied, meaning that the assumption about the multinormal distribution of the model parameter vector $w$ was acceptable.

The hypothesis of the log-normal distribution of the initial diacetyl versus $\mathrm{CO}_{2}$ yield $\left(Y_{0}\right)$ was also verified using the modified Anderson-Darling statistic (2). The hypothesis could not be rejected at a 0.05 significance level. A graphical verification was provided by the statistical plot in Figure $3 \mathrm{~B}$. The parameters of the log-normal distribution of the initial diacetyl yield $(\lambda$ and $\mu$ ) are reported in Table III together with their confidence intervals.

\section{Comparison of Various Sources of Uncertainty}

When predicting the diacetyl concentration for a new fermentation run, three sources of uncertainty were considered: the mea-

TABLE III

\begin{tabular}{|c|c|c|c|c|c|c|c|}
\hline \multirow[b]{2}{*}{ Symbol } & \multirow[b]{2}{*}{ Units } & \multicolumn{3}{|c|}{ Value with $95 \%$ Confidence Limits } & \multirow[b]{2}{*}{ Distribution $^{a}$} & \multirow[b]{2}{*}{ df } & \multirow[b]{2}{*}{ Source } \\
\hline & & Min. & Median & Max. & & & \\
\hline$\overline{K_{A}}$ & $\mathrm{hr}^{-1}$ & $8.3 \times 10^{-3}$ & $10.2 \times 10^{-3}$ & $12.4 \times 10^{-3}$ & Log-normal & 75 & Determined from runs R01-R04 and R06-R09 using equation 17 \\
\hline$K_{A \theta}$ & ${ }^{\circ} \mathrm{C}^{-1}$ & 0.129 & 0.176 & 0.222 & Normal & 75 & Idem \\
\hline$K_{Y}$ & $\mathrm{~g}^{-1} \cdot \mathrm{L}$ & 0.162 & 0.203 & 0.255 & Log-normal & 75 & Idem \\
\hline$\lambda$ & None & 0.24 & 0.34 & 0.54 & $\chi^{2}$ & 13 & Determined from runs R01-R11 and R13-R15 using equation 22 \\
\hline$\mu$ & None & -1.78 & -1.59 & -1.39 & Student & 13 & Determined from runs R01-R11 and R13-R15 using equation 21 \\
\hline$\sigma_{A}$ & $\mathrm{mg} \cdot \mathrm{L}^{-1}$ & 0.092 & 0.106 & 0.125 & $\chi^{2}$ & 75 & Determined from runs R01-R04 and R06-R09 using equation 18 \\
\hline
\end{tabular}

Numerical Values of the Coefficients in the Diacetyl Concentration Model

a Assumed distribution for the estimator. 
surement noise, the imperfect knowledge of the model parameters, and the batch-to-batch variation of the initial diacetyl versus $\mathrm{CO}_{2}$ yield $\left(Y_{0}\right)$. As far as the initial diacetyl yield was concerned, two practical situations have been distinguished: 1) the diacetyl concentration was not measured and the a priori distribution of the yield had to be considered; and 2) in-line diacetyl measurements were performed and an initial yield could be determined for each specific run, thus reducing the uncertainty. In the following, the effect of each source of uncertainty is examined separately in order to state its relative importance.

The effect of the measurement noise is illustrated in Figure 4A. The scatter of the experimental data is particularly obvious between 150 and $250 \mathrm{hr}$. Confidence intervals bracket experimental data tightly in this region. After $300 \mathrm{hr}$, experimental data are smoother and in good agreement with model simulations. Large confidence intervals are maintained, however, due to the hypothesis of constant variance of the measurement noise. The first two measurements suggest a lag in the diacetyl formation. This lag was not observed systematically and was not included in the present model but might become significant for fermentations performed without mechanical stirring.

The effect of the model parameter uncertainty $\left(K_{A}, K_{A \theta}\right.$, and $\left.K_{Y}\right)$ is illustrated in Figure 4B. The first part of the fermentation $(25 \mathrm{hr})$ is not affected by these three parameters. The sensitivity to the mentioned parameters, which enter the diacetyl reduction model and the descriptive yield dynamic, is mostly apparent around the maximum of the diacetyl concentration and afterwards. Unlike the preceding case, this is an uncertainty affecting the true (rather than measured) concentration.

When in-line diacetyl measurements are not performed, the uncertainty on the initial diacetyl yield must be taken into account through its a priori probability distribution. The very large confidence interval shown in Figure 4C should include the true diacetyl concentration for most runs. For many runs, however, these limits are quite conservative. For example, run R11 (Figure 4C) has one of the lowest yields, and decisions based on the upper limit of the confidence interval, such as the duration of the diacetyl rest phase, would be substantially in error.

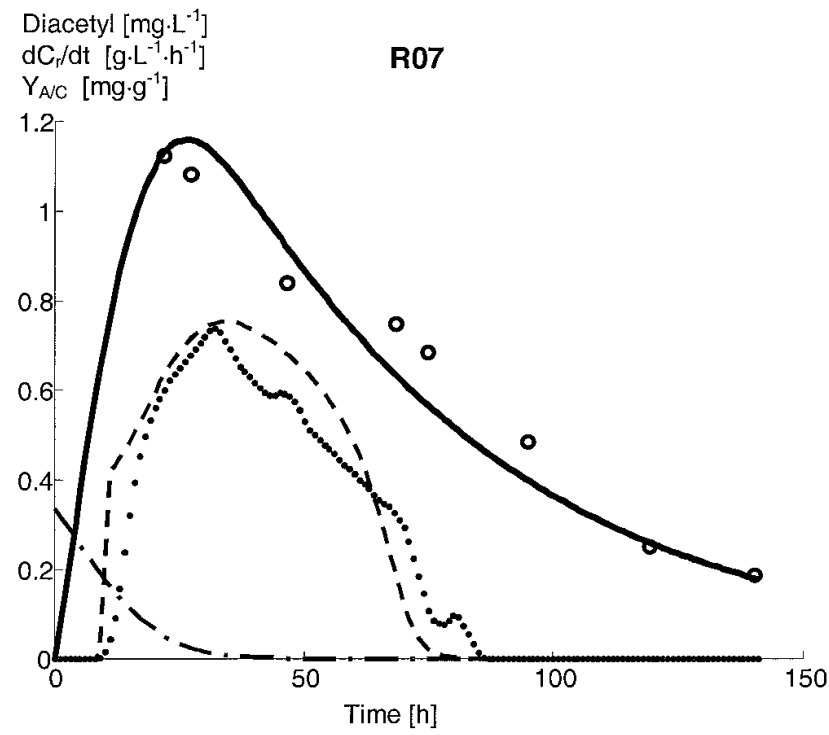

Fig 2. Prediction of the diacetyl concentration in a typical fermentation experiment. Measured diacetyl concentration (o), simulated diacetyl concentration $(-)$, measured $\mathrm{CO}_{2}$ evolution rate $(\bullet \bullet)$, simulated $\mathrm{CO}_{2}$ evolution rate $(--)$, and simulated diacetyl versus $\mathrm{CO}_{2}$ yield $(-\cdot-)$. The residual (unexplained) variance in the measured diacetyl concentration represents $6 \%$ of the total variance.
A way to determine tighter confidence limits is to perform in-line diacetyl measurements soon after the beginning of the alcoholic fermentation. Even a limited number of measurements significantly improve the estimation of the yield for that specific batch. In the same run, R11 (Fig. 4D), two measurements were considered, at 10 and $20 \%$ of the total $\mathrm{CO}_{2}$ produced (or, equivalently, of the total consumed fermentable sugar). The upper limit of the confidence interval is reduced by a factor of almost 2 compared to that in Figure 4C. By chance, the two selected measurements are rather high and the diacetyl concentration still appears slightly overestimated. If the number of measurements taken into account is increased, the confidence interval shrinks further and the overestimation disappears.

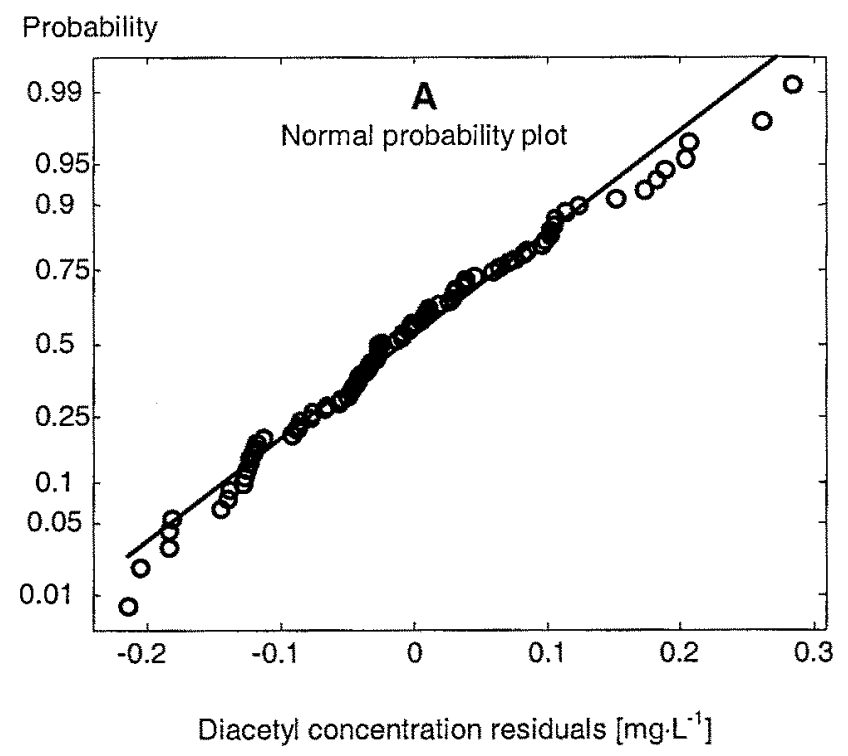

Probability

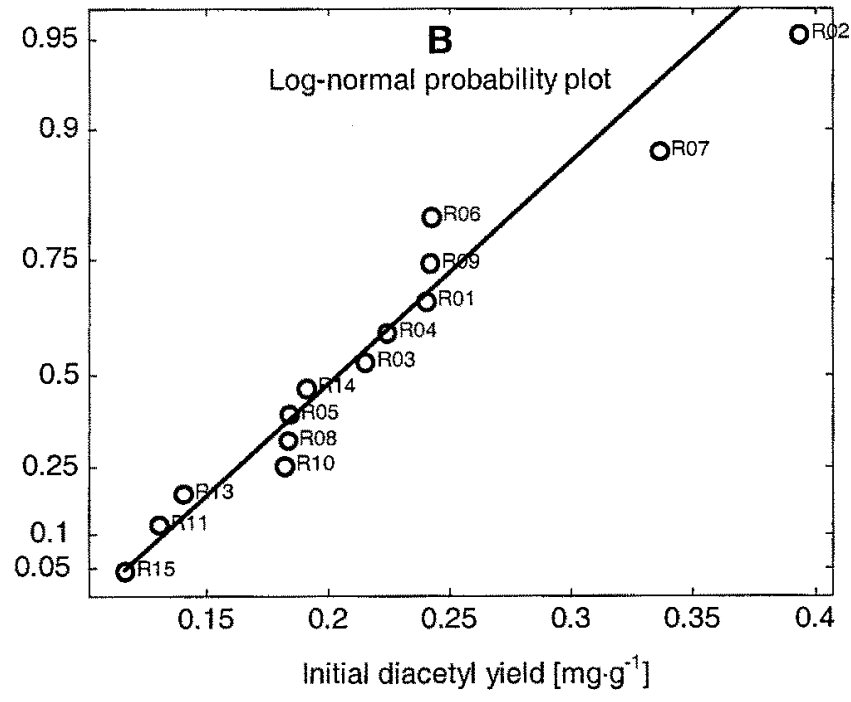

Fig 3. Graphical verification of the main statistical assumptions. Experimental (o) and theoretical (-) probability distributions. Probability scales are nonlinear, such as to make the theoretical cumulative distribution functions linear. A, diacetyl model residuals (measurement noise) are likely to come from a normal probability distribution. B, initial diacetyl yield $\left(Y_{0}\right)$ is reasonably well described by a log-normal probability distribution. 

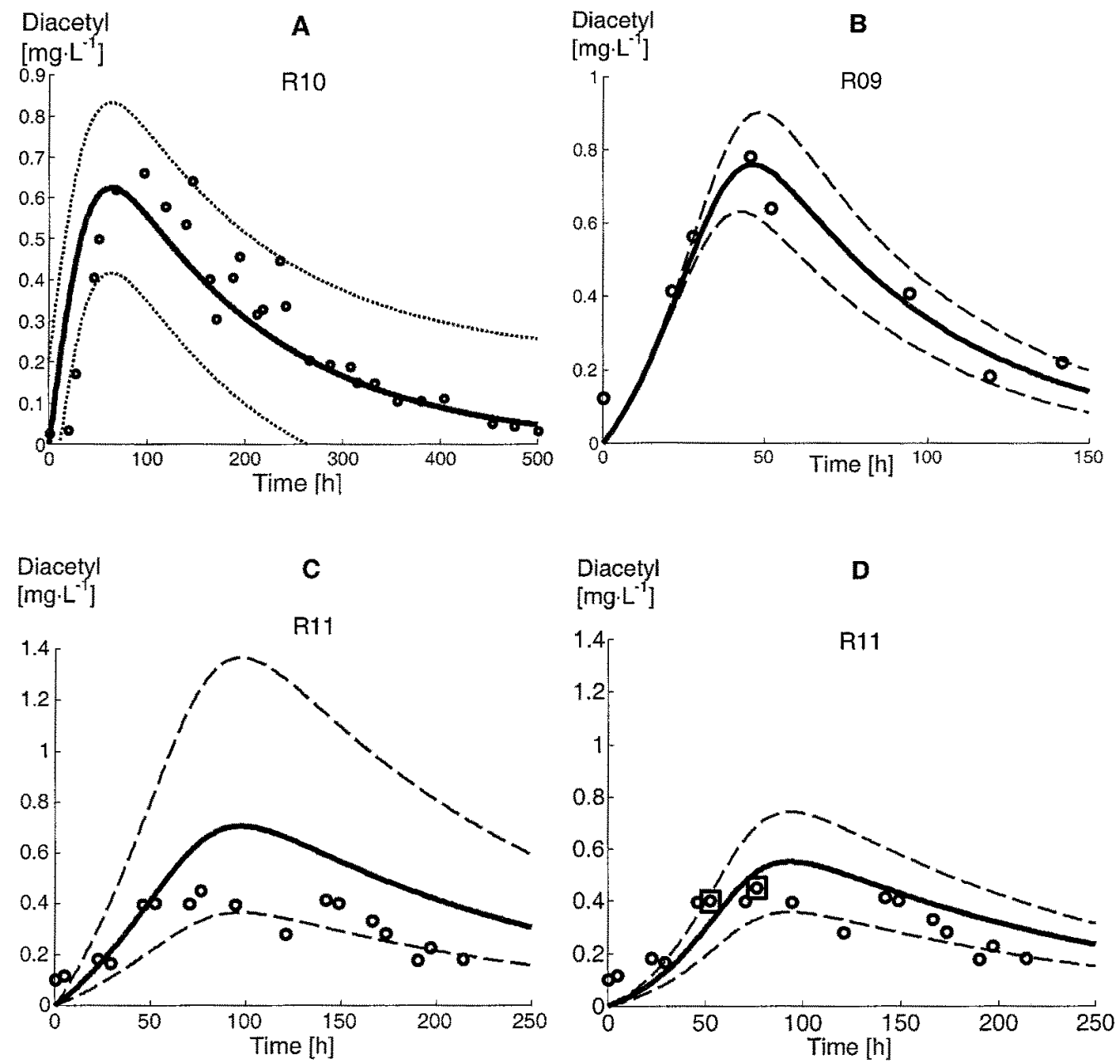

Fig 4. Effect of the various sources of uncertainty, taken separately, on the prediction of the diacetyl concentration. Experimental data (o), median concentration (-), 95\% confidence limits for the true concentration (- - ), and $95 \%$ confidence limits for the measured concentration ( $\cdots \cdots . .$.$) . A,$ uncertainty due to measurement errors. B, uncertainty due to the model parameters $K_{A}, K_{A \theta}$, and $K_{Y}$. $\mathbf{C}$, uncertainty due to the batch-to-batch variation of the initial diacetyl versus $\mathrm{CO}_{2}$ yield $\left(Y_{0}\right)$. D, uncertainty due to the initial diacetyl versus $\mathrm{CO}_{2}$ yield $\left(Y_{0}\right)$, estimated specifically for the considered batch using the measurements marked by squares $(\odot)$.
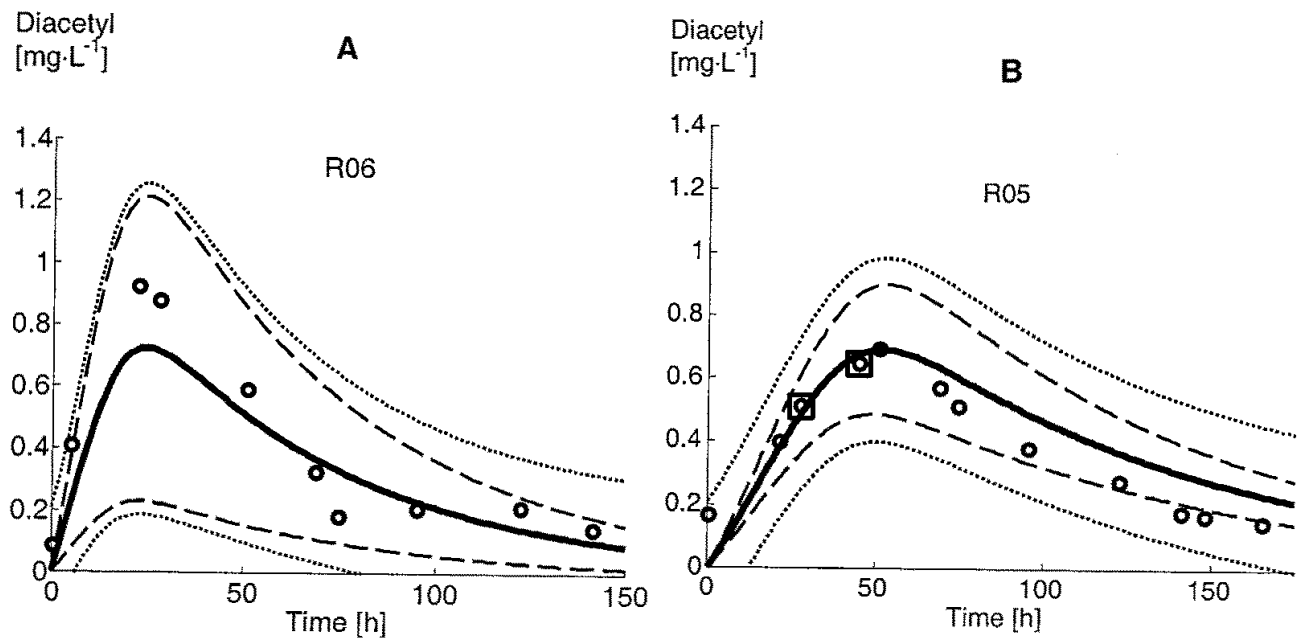

Fig 5. Prediction of the diacetyl concentration, taking into account the various sources of uncertainty simultaneously. Experimental data (o), median concentration (-), $95 \%$ confidence limits for the true concentration $(--)$, and $95 \%$ confidence limits for the measured concentration ( $\cdots \cdots .$.$) . A, If no$ real-time diacetyl measurements were performed, the a priori distribution for the initial diacetyl yield $\left(Y_{0}\right)$ had to be taken into account. B, If diacetyl measurements marked by squares $(\odot)$ were available, a batch-specific yield and tighter confidence limits for the true concentration could be determined. 


\section{Prediction of Plausible Ranges of Diacetyl Concentration}

In practice, all sources of uncertainty must be accounted for simultaneously. It appeared from the previous discussion and from Figure 4 that the uncertainty due to the initial diacetyl yield was dominant but could be substantially reduced by one or two realtime measurements. Hence, it is worth distinguishing between the cases in which diacetyl measurements are and are not available. In Figure 5A, the combined effect of all uncertainties is shown, supposing that no in-line diacetyl measurements were performed. It happened that, in this particular run, the initial diacetyl yield had a typical value and the median prediction was representative of the

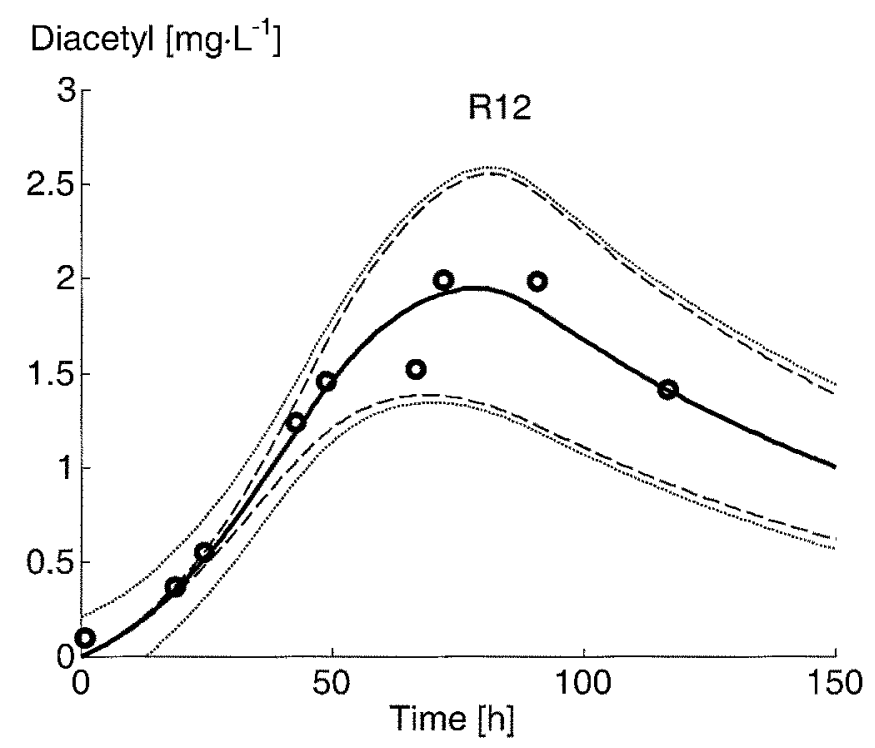

Fig 6. Prediction of the diacetyl concentration for the Cedarex wort. Experimental data (o), median concentration (-), 95\% confidence limits for the true concentration (- -$)$, and $95 \%$ confidence limits for the measured concentration (…...). true concentration. However, the use of the a priori probability distribution for the diacetyl yield produced quite large confidence intervals. In Figure 5B, the initial diacetyl yield was estimated specifically for the considered run using two measurements. The confidence limits for the true concentration are much tighter.

\section{Model Adaptation to a Different Wort}

The possibility of applying the diacetyl model to the concentrated Cedarex wort was investigated in run R12 (Fig. 6). In the alcoholic fermentation model, a correction had to be made by modifying the "specific" fermentation rate parameter $K_{v}$ from 0.0474 (Table II) to $0.0600 \mathrm{hr}^{-1}$, reflecting a slight overall acceleration of the alcoholic fermentation in otherwise similar operating conditions. Dependence of the fermentation rate on the wort composition is well known in brewing practice and is generally explained by differences in concentrations of growth factors and/or unsaturated fatty acids. All other parameters listed in Table II remained unchanged. No significant difference in the biomass growth was observed in this run compared to the other runs in the database (Fig. 7). The diacetyl model had to be modified, however, by allowing diacetyl to be produced later during the alcoholic fermentation, i.e., slowing down the yield decrease: the determined value of the parameter $K_{\mathrm{Y}}$ (using equation 17) was 0.028 instead of $0.203 \mathrm{~g}^{-1} \cdot \mathrm{L}$. Parameters $K_{A}$ and $K_{A \theta}$ were left unchanged (Table III). Thus, the high maximum diacetyl concentration in this run $\left(2 \mathrm{mg} \cdot \mathrm{L}^{-1}\right.$ instead of an average of $0.7 \mathrm{mg} \cdot \mathrm{L}^{-1}$ in the other runs) was due to a longer production period rather than to a higher yield. The estimated initial diacetyl yield for run R12 was $0.13 \mathrm{mg} \cdot \mathrm{g}^{-1}$, one of the lowest among all runs. The parameters $\lambda$ and $\mu$, describing the probability distribution of the initial yield, are expected to change for the Cedarex wort, but this could be confirmed only if more (at least 10) runs were available.

In the light of the data provided by run R12, it can be speculated that the constant-yield model of Engasser et al (6) might indeed be appropriate for some sorts of wort and/or yeast strains, but this would be a very special case and needs further experimental verification.
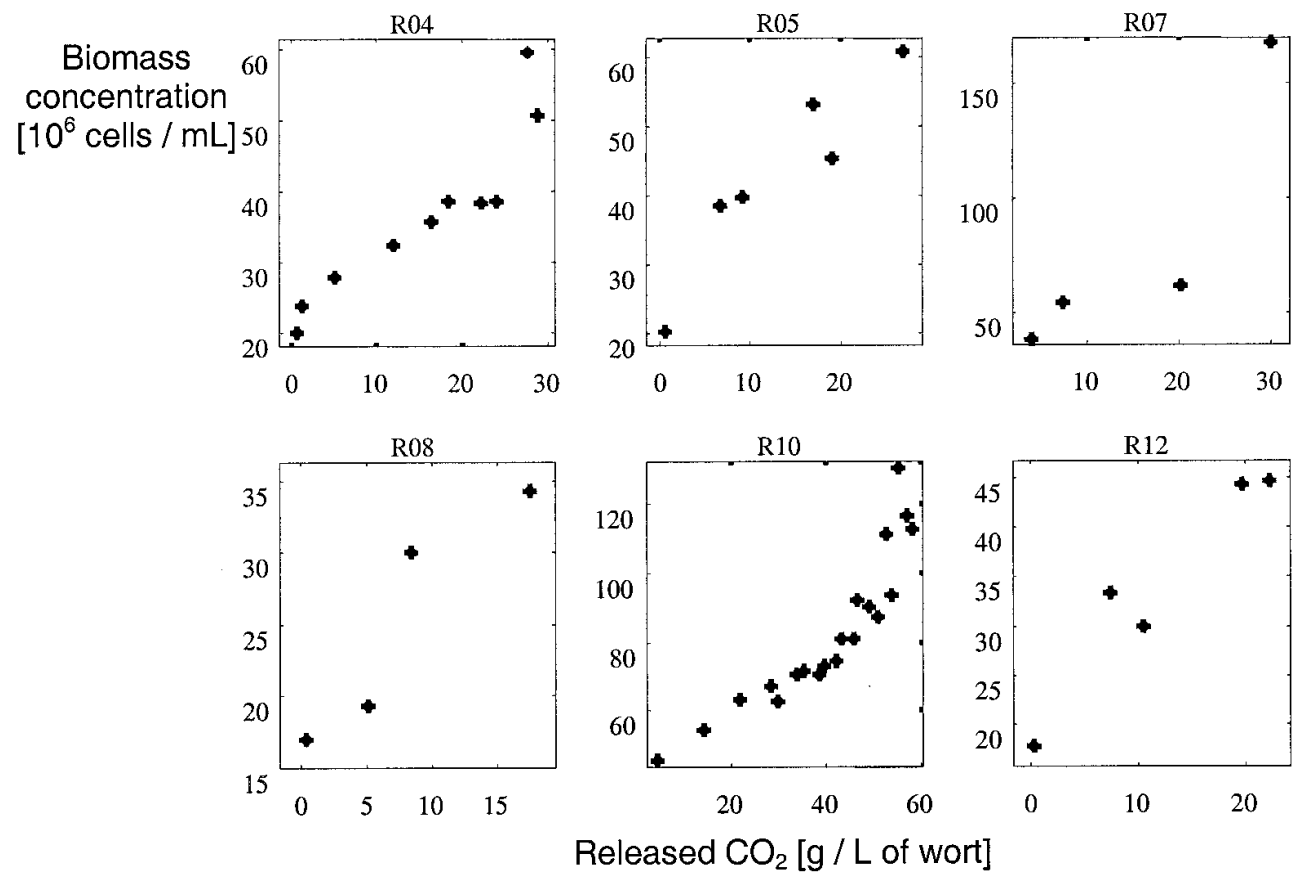

Fig 7. Relationship between the biomass concentration and the alcoholic fermentation progress. Data is plotted for released $\mathrm{CO}_{2}$ comprised between 0.01 and 0.95 of the total amount in order to avoid distortions due to dissolved $\mathrm{CO}_{2}$ and inaccurate biomass measurements after yeast flocculation. Within the accuracy of the biomass measurement, the relationship between the biomass concentration and the alcoholic fermentation progress appears linear. 


\section{CONCLUSION}

A dynamic model predicting the diacetyl concentration during alcoholic fermentation of beer has been established. In spite of high experimental variability, not explained by measured operating conditions and routinely measured wort composition, a probabilistic framework was adopted. The effects of the measurement errors, of the uncertainty in the model parameters, and of the batch-to-batch variability were examined separately and in combination. It was demonstrated that the effect of the batch-tobatch variability was dominant. This effect could be substantially reduced for each specific batch, however, by a limited number of in-line diacetyl measurements during the early stages of the alcoholic fermentation.

The model did not attempt to explain the intricacy of the metabolic pathways leading to diacetyl formation but was intended to be useful from a process engineering perspective. It was based on the dynamic of alcoholic fermentation, which is relatively well known and routinely measured in industry. The probabilistic framework provided realistic confidence intervals for the diacetyl concentration. The upper boundary of such a confidence interval could be used for making well-informed decisions concerning the required "diacetyl rest" and beer production scheduling in general.

The adaptation of the developed model to a new sort of wort required the modification of a limited number of coefficient values. Investigation of the effects of the wort composition, the yeast strain, and the tank geometry and agitation is the subject of future work.

\section{LITERATURE CITED}

1. Andrés-Toro, B., Giron-Sierra, J. M., Lopez-Orozco, J. A., Fernandez-Condé, C., Peinado, J. M., and Garcia-Ochoa, F. A kinetic model for beer production under industrial operation conditions. Math. Comput. Simulat. 48:65-74, 1998.

2. Bury, K. Pages 27-48 and 120-237 in: Statistical Distributions in Engineering. Cambridge University Press, Cambridge, UK, 1999.

3. Coleman, T., Branch, M. A., and Grace, A. Pages 2.17-2.22 in: Optimization Toolbox for Use with Matlab: User's Guide. The MathWorks, Inc., Natick, MA, 1999.

4. Corrieu, G., Trelea, I. C., and Perret, B. On-line estimation and prediction of density and ethanol evolution in the brewery. Tech. $Q$. Master Brew. Assoc. Am. 37:173-181, 2000.
5. Daoud, I. S., and Searle, B. A. On-line monitoring of brewery fermentation by measurement of $\mathrm{CO}_{2}$ evolution rate. J. Inst. Brew. 96:297-302, 1990.

6. Engasser, J. M., Marc, I., Moll, M., and Duteurtre, B. Kinetic modelling of beer fermentation. Proc. Congr. Eur. Brew. Conv. 18:579-586, 1981.

7. Garcia, A. I, Garcia, L. A., and Diaz, M. Modelling of diacetyl production during beer fermentation. J. Inst. Brew. 100:179-183, 1994.

8. Gee, D. A., and Ramirez, W. F. A flavour model for beer fermentation. J. Inst. Brew. 100:321-329, 1994.

9. Landaud, S., Lieben, P., and Picque, D. Quantitative analysis of diacetyl, pentanedione and their precursors during beer fermentation, by an accurate GC/MS method. J. Inst. Brew. 104:93-99, 1998.

10. Mathis, C., Pons, M. N., and Engasser, J. M. Development of an online method for monitoring of vicinal diketones and their precursors in beer fermentation. Anal. Chem. Acta 279:59-66, 1993.

11. Meilgaard, M. C., Reid, D. S., and Wyborski, K. A. Reference standards for the beer flavor terminology system. J. Am. Soc. Brew. Chem. 36:119-128, 1982.

12. Sivia, D. S. Data Analysis: A Bayesian Tutorial. Oxford University Press, Oxford, UK, 1998.

13. Stassi, P., Rice, J. F., Munroe, J. H., and Chicoye, E. Use of $\mathrm{CO}_{2}$ evolution rate for the study and control of fermentation. Tech. $Q$. Master Brew. Assoc. Am. 24(2):44-50, 1987.

14. Tada, S., Takeuchi, T., Sone, H., Yamano, S., Schofield, M. A., Hammond, J. R. M., and Inue, T. Pilot-scale brewing with industrial scale yeasts which produce the alpha-acetolactate decarboxylase of Acetobacter aceti ssp. xylinum. Proc. Congr. Eur. Brew. Conv. 25:369-376, 1995.

15. Titica, M., Landaud, S., Trelea, I. C., Latrille, E., Corrieu, G., and Cheruy, A. Modelling of higher alcohol and ester production kinetics based on $\mathrm{CO}_{2}$ emission, with a view to beer flavor control by temperature and top pressure. J. Am. Soc. Brew. Chem. 54:167-174, 2000.

16. Trelea, I. C., Latrille, L., Landaud, S., and Corrieu, G. Reliable estimation of the key variables and of their rates of change in alcoholic fermentation. Bioproc. Biosyst. Eng. 24:227-237, 2001.

17. Trelea, I. C., Titica, M., Landaud, S., Latrille, E., Corrieu, G., and Cheruy, A. Predictive modelling of brewing fermentation: From knowledge-based to black-box models. Math. Comput. Simulat. 56:405-424, 2001.

18. Wainwright, T. Diacetyl—A review. J. Inst. Brew. 79:451-470, 1973.

[Received May 30, 2001. Accepted January 8, 2002.]

\section{APPENDIX I. RELATIONSHIP BETWEEN ALCOHOLIC FERMENTATION AND CELL GROWTH}

The mathematical form of equation 1 was suggested by the classical microbial growth kinetic with substrate limitation and product inhibition:

$$
\frac{d X(t)}{d t}=\mu\left(\theta, C_{d}, S, E\right) X(t)
$$

In the considered experiments, near proportionality was observed between cell growth and the progress of the alcoholic fermentation as described by the $\mathrm{CO}_{2}$ release (Fig. 7):

$$
C_{p}(t)=Y_{C / X}\left\lfloor X(t)-X_{0}\right\rfloor
$$

Strict proportionality implies a constant yield $Y_{\mathrm{C} / \mathrm{X}}$. Equation 1 can be obtained by substituting $X(t)$ from equation A2 into equation $\mathrm{A} 1$ and using the notation:

$$
\mu\left(\theta, C_{d}, S, E\right)=v\left[\theta(t), D_{d}(t)\right] \cdot \frac{S(t)}{K_{S}+S(t)} \cdot \frac{1}{1+\left[E(t) / K_{E}\right]^{2}}
$$

$$
K_{X}=\frac{1}{Y_{C / X}}
$$

Strict proportionality between yeast growth and alcoholic fermentation progress is not expected to hold in all cases. For example, the substrate limitation and the product (ethanol and dissolved $\mathrm{CO}_{2}$ ) inhibition constants are not necessarily the same for alcoholic fermentation and growth. Yeast settling in naturally (as opposed to mechanically) agitated tanks may also invalidate equation A2. This is why equation 1 is said to be constructed only by analogy with the growth kinetic (equation A1) and not derived from it. Equation 1 is still expected to remain valid (with suitably chosen limitation and inhibition constants) even if the proportionality expressed by equation A2 does not hold. 


\section{APPENDIX II. NOMENCLATURE}

\begin{tabular}{|c|c|c|}
\hline Symbol & Units & Significance \\
\hline$A$ & $\mathrm{mg} \cdot \mathrm{L}^{-1}$ & "Total" or "potential" diacetyl concentration $=$ diacetyl + equivalent $\alpha$-acetolactate \\
\hline$A_{i j}$ & $\mathrm{mg} \cdot \mathrm{L}^{-1}$ & Predicted total diacetyl concentration for sample $j$ of run $i$ \\
\hline$\underline{A}$ & $\mathrm{mg} \cdot \mathrm{L}^{-1}$ & Lower predicted boundary for the true total diacetyl concentration, at a specified confidence level \\
\hline $\bar{A}$ & $\mathrm{mg} \cdot \mathrm{L}^{-1}$ & Upper predicted boundary for the true total diacetyl concentration, at a specified confidence level \\
\hline$a_{i j}$ & $\mathrm{mg} \cdot \mathrm{L}^{-1}$ & Measured total diacetyl concentration in sample $j$ of run $i$ \\
\hline$\underline{a}$ & $\mathrm{mg} \cdot \mathrm{L}^{-1}$ & Lower predicted boundary for the measured total diacetyl concentration, at a specified confidence level \\
\hline $\bar{a}$ & $\mathrm{mg} \cdot \mathrm{L}^{-1}$ & Upper predicted boundary for the measured total diacetyl concentration, at a specified confidence level \\
\hline$C_{d}$ & $g \cdot \mathrm{L}^{-1}$ & Carbon dioxide dissolved in the wort \\
\hline$C_{d 0}$ & $\mathrm{~g} \cdot \mathrm{L}^{-1}$ & Dissolved carbon dioxide concentration at the operating conditions of the central point of the experimental design \\
\hline$C_{p}$ & $g \cdot \mathrm{L}^{-1}$ & Carbon dioxide produced in the alcoholic fermentation, per liter of wort \\
\hline$C_{r}$ & $g \cdot \mathrm{L}^{-1}$ & Carbon dioxide released during alcoholic fermentation, per liter of wort \\
\hline$C_{\text {sat }}$ & $g \cdot \mathrm{L}^{-1}$ & Dissolved carbon dioxide concentration at saturation \\
\hline$D$ & $g \cdot \mathrm{L}^{-1}$ & Wort density \\
\hline$D_{0}$ & $g \cdot \mathrm{L}^{-1}$ & Initial wort density \\
\hline$E$ & $g \cdot \mathrm{L}^{-1}$ & Ethanol concentration \\
\hline$H$ & $\mathrm{~g} \cdot \mathrm{L}^{-1} \cdot \mathrm{mbar}^{-1}$ & Solubility of the carbon dioxide in the wort \\
\hline$I$ & None & Set of experimental runs used for model parameter identification \\
\hline$i$ & None & Index of an experimental run in set $I$ \\
\hline$j$ & None & Index of a sample in an experimental run \\
\hline$K_{v}$ & $\mathrm{hr}^{-1}$ & Maximum "specific" fermentation rate at the operating conditions of the central point of the experimental design \\
\hline$K_{\mathrm{v} \theta}$ & ${ }^{\circ} \mathrm{C}^{-1}$ & Temperature effect on the alcoholic fermentation rate constant \\
\hline$K_{\mathrm{v} C}$ & $\mathrm{~g}^{-1} \cdot \mathrm{L}$ & Dissolved carbon dioxide effect on the alcoholic fermentation rate constant \\
\hline$K_{0}$ & $\mathrm{~g} \cdot \mathrm{L}^{-1} \cdot \mathrm{mbar}^{-1}$ & Solubility of the carbon dioxide in the wort at $0^{\circ} \mathrm{C}$ \\
\hline$K_{1}, K_{2}$ & ${ }^{\circ} \mathrm{C}^{-1}$ & Temperature effect on the carbon dioxide solubility constants \\
\hline$K_{A}$ & $\mathrm{hr}^{-1}$ & Diacetyl reduction rate constant \\
\hline$K_{A \theta}$ & ${ }^{\circ} \mathrm{C}^{-1}$ & Temperature effect on diacetyl reduction rate constant \\
\hline$K_{E}$ & $g \cdot \mathrm{L}^{-1}$ & Ethanol inhibition constant \\
\hline$K_{S}$ & $\mathrm{~g} \cdot \mathrm{L}^{-1}$ & Substrate saturation constant \\
\hline$K_{X}$ & $\begin{array}{l}\mathrm{g} \cdot \mathrm{L}^{-1} \\
\left(10^{6} \text { cells }\right)^{-1}\end{array}$ & Initial cell concentration constant \\
\hline$K_{Y}$ & $\mathrm{~g}^{-1} \cdot \mathrm{L}$ & Diacetyl versus carbon dioxide yield dynamic constant \\
\hline$L$ & None & Minus logarithm of the parameter likelihood function \\
\hline$M$ & $\mathrm{mg}^{2} \cdot \mathrm{L}^{-2}$ & Sum of squares of the errors between predicted and measured diacetyl concentrations \\
\hline$n$ & None & Total number of diacetyl measurements used for model parameter identification \\
\hline$n_{i}$ & None & Number of diacetyl measurements from run $i$ used for model parameter identification \\
\hline$n_{r}$ & None & Number of runs used for the estimation of the parameters $\lambda$ and $\mu$ \\
\hline$n_{w}$ & None & Number of elements in vector $w$ \\
\hline$p$ & mbar & Top pressure in the fermentation tank \\
\hline$R$ & none & Wort refractive index \\
\hline$R_{0}$ & none & Initial wort refractive index \\
\hline$S$ & $\mathrm{~g} \cdot \mathrm{L}^{-1}$ & Fermentable sugar concentration \\
\hline$S_{0}$ & $g \cdot \mathrm{L}^{-1}$ & Initial fermentable sugar concentration \\
\hline$t$ & $\mathrm{hr}$ & Time since yeast pitching \\
\hline$U_{a}$ & None & $\begin{array}{l}\text { Inverse cumulative probability function for a standard normal distribution, at level } \alpha \text {. Value below which a fraction } \alpha \text { of the } \\
\text { possible values falls }\end{array}$ \\
\hline$V$ & $\mathrm{NA}^{\mathrm{a}}$ & Estimated covariance matrix of $w^{*}$ \\
\hline$w$ & NA & Vector of unknown model parameters \\
\hline$w^{*}$ & NA & Vector of most-probable model parameters \\
\hline$X$ & $10^{6}$ cells $\cdot \mathrm{ml}^{-1}$ & Yeast concentration \\
\hline$X_{0}$ & $10^{6}$ cells $\cdot \mathrm{ml}^{-1}$ & Initial yeast concentration \\
\hline$Y_{0}$ & $\mathrm{mg} \cdot \mathrm{g}^{-1}$ & Initial diacetyl versus carbon dioxide yield \\
\hline$Y_{0 i}$ & $\mathrm{mg} \cdot \mathrm{g}^{-1}$ & Initial diacetyl versus carbon dioxide yield in experimental run $i$ \\
\hline$Y_{A / C}$ & $\mathrm{mg} \cdot \mathrm{g}^{-1}$ & Diacetyl versus carbon dioxide yield \\
\hline$Y_{D / C}$ & $g \cdot g^{-1}$ & Density versus carbon dioxide yield \\
\hline$Y_{E / C}$ & $g \cdot g^{-1}$ & Ethanol versus carbon dioxide yield \\
\hline$Y_{R / C}$ & $\mathrm{~g}^{-1} \cdot \mathrm{L}$ & Wort refractive index versus carbon dioxide yield \\
\hline$Y_{S / C}$ & $g \cdot g^{-1}$ & Fermentable sugar versus carbon dioxide yield \\
\hline$\theta$ & ${ }^{\circ} \mathrm{C}$ & Wort temperature \\
\hline$\theta_{0}$ & ${ }^{\circ} \mathrm{C}$ & Fermentation temperature the central point of the experimental design \\
\hline$\lambda$ & None & Standard deviation of the logarithm of $Y_{0}$ \\
\hline$\mu$ & None & Mean value of the logarithm of $Y_{0}$ \\
\hline$\mu$ & $\mathrm{hr}^{-1}$ & Specific cell growth rate \\
\hline$v$ & $\mathrm{hr}^{-1}$ & "Specific" rate of the alcoholic fermentation \\
\hline$\sigma_{A}$ & $\mathrm{mg} \cdot \mathrm{L}^{-1}$ & Measurement standard deviation of the diacetyl concentration \\
\hline
\end{tabular}

a Not applicable. 